\title{
BMJ Open Early-life famine exposure and rheumatoid arthritis in Chinese adult populations: a retrospective cohort study
}

\author{
Chunyu Liu, ${ }^{1,2}$ Xiangrui Meng, ${ }^{1}$ Hao Zhang, ${ }^{2,3}$ Fan Yang, ${ }^{2}$ Xiaoyu Pan, ${ }^{4}$ \\ Kun Tang (iD ${ }^{1}$
}

To cite: Liu C, Meng X, Zhang $\mathrm{H}$, et al. Early-life famine exposure and rheumatoid arthritis in Chinese adult populations: a retrospective cohort study. BMJ Open 2021;11:e043416. doi:10.1136/ bmjopen-2020-043416

- Prepublication history and additional supplemental materia for this paper are available online. To view these files, please visit the journal online (http://dx.doi.org/10.1136/ bmjopen-2020-043416).

$\mathrm{CL}$ and $\mathrm{XM}$ are joint first authors.

Received 02 August 2020 Accepted 02 June 2021

Check for updates

(c) Author(s) (or their employer(s)) 2021. Re-use permitted under CC BY-NC. No commercial re-use. See rights and permissions. Published by BMJ.

${ }^{1}$ Vanke School of Public Health, Tsinghua University, Beijing, China

${ }^{2}$ Department of Epidemiology and Biostatistics, Peking University School of Public Health, Beijing, China

${ }^{3} J o h n s$ Hopkins University Bloomberg School of Public Health, Baltimore, Maryland, USA

${ }^{4}$ Department of Orthopedics, Peking University Third Hospital, Beijing, China

Correspondence to

Dr Kun Tang;

tangk@mail.tsinghua.edu.cn

\section{ABSTRACT}

Objective This study aimed to explore the association between famine exposure in early life and the odds of rheumatoid arthritis (RA) in adulthood.

Design A population-based retrospective cohort study. Setting China.

Participants A total of 111706 participants (1775 with RA) born from 1956 to 1964 were selected from the baseline survey of a large cohort in China.

Primary and secondary outcome measures Four famine exposure groups were generated based on dates of birth, namely prenatal-exposed, infant-exposed, preschoolexposed and non-exposed groups. Logistic regressions were used to explore the association between famine exposure and self-reported RA in adulthood, adjusting for sex, region, monthly income, highest education, alcohol consumption, tobacco use, body mass index (BMI) and metabolic equivalent tasks. Analyses were also performed with stratification for sex (female or male), residing region (urban or rural), famine severity (severe or non-severe) and BMl $(\geq 24$ or $<24)$.

Results The study included 1775 (1.59\%) RA cases and 109931 (98.41\%) non-RA controls. Among them, 22413 (20.06\%) were prenatal-exposed, 14899 (13.34\%) were infant-exposed and 34356 (30.76\%) were preschoolexposed. Prenatal exposure to famine was not associated with onset of RA in adulthood. Infant-exposed group and preschool-exposed group had significantly elevated odds of getting RA compared with non-exposed group (infant-exposed: $\mathrm{OR}=1.44,95 \% \mathrm{Cl} 1.24$ to 1.67 ; preschoolexposed: $\mathrm{OR}=1.38,95 \% \mathrm{Cl} 1.22$ to $1.57, \mathrm{p}<0.001$ ), and the relationship was stronger among women, urban residents and participants with $\mathrm{BMI} \geq 24$. Similar results were additionally observed when an age-balanced control group was used.

Conclusions Exposure to the Great Chinese Famine in early life after birth especially in infancy may be associated with a higher risk of RA in adulthood. Strengthening earlylife nutrition could be an implication to prevent future RA.

\section{INTRODUCTION}

Rheumatoid arthritis (RA) is a common chronic systemic inflammatory autoimmune disease causing huge burden in terms of health and financial costs. ${ }^{1-3}$ It affects about $1 \%$ of the global population and occurs at all

\section{Strengths and limitations of this study}

This population-based cohort study is the first to explore the association between famine exposure in early life and rheumatoid arthritis in adulthood.

- The large sample was selected with a wide geographical distribution, covering 10 provinces in China.

- The prevalence of rheumatoid arthritis might be misreported using self-reported data.

- Due to its retrospective design, the study lacks individual-level measurements of famine exposure in early life.

ages, mainly prevalent among middle-aged women. ${ }^{4}$

There had been evidence showing that undernutrition during childhood could increase the risk of many chronic diseases in adulthood, including metabolic syndrome (MetS), hypertension, type 2 diabetes and coronary heart disease. ${ }^{5-7}$ Inflammatory mediators such as $\mathrm{C}$ reactive protein, interleukin 6 and tumour necrosis factor- $\alpha$ are also frequently elevated in patients with these chronic diseases, ${ }^{89}$ as well as in the sera of patients many years before the clinical onset of RA, suggesting a critical role of the immunopathogenesis of these diseases. Meanwhile, a study showed that early-life malnutrition impacted the development of the immune system. ${ }^{10}$ Thus, we had speculation that earlylife malnutrition may also be related to the increased risk of RA in adulthood, which had not been studied before.

The Chinese famine of 1959-1961, one of the largest famines in human history with approximately 30 million excess deaths and nearly all provinces in China affected, ${ }^{11}$ offers a unique opportunity to test such speculation at the population level. The relationships between early-life malnutrition due to the Chinese famine and later-life diabetes, ${ }^{12}$ MetS, ${ }^{513}$ hypertension, ${ }^{14}$ short height ${ }^{15}$ and 
overweight ${ }^{16}$ have been explored. Two previous studies also used this paradigm and demonstrated higher prevalence of arthritis in adulthood among individuals exposed to the Chinese famine during early life. ${ }^{17}{ }^{18}$ However, arthritis was regarded as a single outcome in both studies, while arthritis was actually a mixture of osteoarthritis $(40 \%)$, RA (17\%) and other types of arthritis (43\%). Because immune pathways pathogenically drive articular inflammation in RA, but not in osteoarthritis, research as a whole might yield confusing results. Thus, it is necessary to explore RA as a specific outcome.

This study focused on the association between earlylife famine exposure and risk of RA in adulthood. We selected participants who were born around the Chinese Great Famine of 1956-1961 from the China Kadoorie Biobank (CKB), a large prospective Chinese cohort, ${ }^{19}$ and explored the association between famine exposure and risk of RA in this data set.

\section{PATIENTS AND METHODS}

\section{Data source and population}

The CKB is a large prospective population-based cohort study on chronic diseases. Data from the baseline survey conducted between 2004 and 2008 were used in the current study. ${ }^{19}$ Participants were recruited from five urban regions and five rural regions in ten provinces in China, selected by disease pattern, odds factors, population stability, health register system, and local commitment and capacity. ${ }^{20}$ Cluster sampling was applied to recruit participants in each region with units of rural villages or urban residential committees. An intervieweradministered electronic questionnaire survey was used to collect data on demographics, socioeconomic status, lifestyle, medical history and reproductive history. Physical measurements including height and weight, hip and waist circumference, bioimpedance, systolic and diastolic blood pressure $(\mathrm{mm} \mathrm{Hg})$, and lung functions were collected at the participants' clinic visit. Finally, data on 515681 participants were collected, with an overall response rate of about $30 \%(26 \%-38 \%$ in rural regions and 16\%-50\% in urban regions). Among 515681 participants, the study excluded those who withdrew without completion (261, $0.05 \%)$, those who attended the survey twice (2208, $0.4 \%), 1$ participant who delivered erroneous data and 320 participants whose age exceeded the study age limitation (between 30 and 79 years old), resulting in 512891 valid baseline data. ${ }^{19}$

The most common definition of the Chinese famine period from 1 January 1959 to 31 December 1961 was adopted after reviewing previous literature.$^{1121} 22$ Famine exposure of individuals was estimated based on their birth date. This study used nine calendar months as gestation length since the duration of conception was reported shorter than the general 40 weeks during the famine period. ${ }^{23}$ Considering the unclear exact start and end of the famine, participants exposed to famine for less than 9 months of the prenatal period, born between
1 January and 30 September in 1959 or 1962, were excluded to ensure the integrity of prenatal exposure. Participants born from 1 January 1956 to 31 December 1957, born from 1 January 1958 to 31 December 1958, born from 1 October 1959 to 31 December 1961, and born from 1 October 1962 to 30 September 1964 were categorised as preschool-exposed group, infant-exposed group, prenatal-exposed group and non-exposed group, respectively. Finally, a total of 111706 participants whose birth dates matched the four groups were included in this study. Among them, there were two participants with missing values for body weight or height; however, due to the small missing data no analytical adjustments were performed.

\section{Outcomes}

History of RA was assessed by the following question: 'Has a doctor ever told you that you had had rheumatoid arthritis? If so, what was the age at first diagnosis?' When answering this question, professional investigators provided participants with identifying information about RA to help them recall accurately.

\section{Covariates}

Sociodemographic and lifestyle characteristics were collected, including sex, urban/rural region, residing area, household income, highest level of education, alcohol consumption, tobacco use, body mass index (BMI) and metabolic equivalent of task hours (MET). Household income was categorised as $<¥ 2500$ (US\$1 $=¥ 7.07$ in October 2019), 2500-4999, 5000-9999, 10000-19 999, 20000-34 999 and $\geq 35000$. Highest education was categorised into non-formal education or primary school, middle school, and college and above. Tobacco use was classified as 'frequent', 'occasional', 'ex-smoker' and 'non-smoker'. Alcohol consumption was classified as 'weekly', 'reduced intake', 'monthly', 'occasional', 'ex-drinker' and 'non-drinker'. BMI was a variable calculated using the weight and height measured during physical examination and was classified as 'BMI $\geq 24$ ' and 'BMI $<24$ ' based on Chinese overweight standards. MET was measured by the product of the number of hours spent per day participating in each activity during the past year and the MET score (2011 Compendium of Physical Activities) for that activity. ${ }^{24}$ Famine severity was categorised by the level of severity in different provinces provided by Peng. ${ }^{25}$ Among the 10 provinces of residing areas, Sichuan, Gansu, Henan, Hunan, Shandong and Guangxi were regarded as severe regions, while Heilongjiang, Jiangsu, Hainan and Zhejiang were regarded as non-severe regions.

\section{Statistical analyses}

Descriptive analysis was applied to show the distribution of sociodemographic, socioeconomic and lifestyle characteristics of participants in the famine exposure groups. Continuous variables were reported as mean and SD. Categorical variables were presented in numbers and 
percentages. Multivariate logistic regressions were used to examine the associations between early-life famine exposure and odds of RA in adulthood. In particular, the strengths of associations were reported using nonexposed group as a reference. To explore the modification effects of sex, residing region, famine severity and BMI on the association between infant famine exposure and RA, analyses were stratified by male/female, rural severe/rural non-severe/urban severe/urban non-severe region and $\mathrm{BMI} \geq 24 / \mathrm{BMI}<24$. Because participants in the exposed groups were older than those in the nonexposed group, the strengths of the associations were reported using both non-exposed and age-balanced groups as a reference, respectively, to minimise the influence of the difference in age. The age-balanced groups were composed of prenatal-exposed and preschoolexposed groups, with the mean age equal to the age of the infant-exposed group (approximately 47 years old). Meanwhile, the age-period-cohort analysis was used as the sensitivity analysis to verify the association excluding the age and period effect; the details of the methods and the results of which are shown in online supplemental file. In subsequent analysis, the differences in sex groups, severity groups and BMI groups were examined by a likelihood ratio test, which compared two models excluding and including the interaction parameters (sex and exposure/severity and exposure/BMI and exposure). For logistic regression models, no covariate was adjusted in model 1. In model 2, region, sex, household income, highest education level, alcohol consumption, tobacco use, BMI and MET were adjusted. OR and $95 \%$ CI were reported. The $\mathrm{p}$ value threshold was set at 0.05 . All statistical analyses were performed using R V.3.6.

\section{Patient and public involvement}

Patients and/or the public were not involved in the design, or conduct, or reporting or dissemination plans of this research.

\section{RESULTS}

In total, 111706 individuals born from 1956 to 1964 were analysed in this study, including 1775 (1.59\%) RA cases and 109931 (98.41\%) non-RA controls. There were 22413 $(20.06 \%)$ people fully exposed to famine in the entire prenatal period, 14899 (13.34\%) participants exposed to famine during the infant period, 34356 (30.76\%) participants exposed to famine during the preschool period and 40038 (35.84\%) participants without famine exposure, among which, respectively, 326 (1.45\%), 289 $(1.94 \%), 619(1.80 \%)$ and $541(1.35 \%)$ people reported RA. Participants' average ages (SD) were 45.43 (1.29) years, 47.69 (1.14) years, 49.12 (1.24) years and 42.48 (1.23) years, respectively. Distributions of region, highest education, household income, alcohol consumption and tobacco use were similar across all exposure groups and no significant differences were observed ( $\chi^{2}$ test, $p>0.05$ ). Participants in the non-exposed group had the highest level of average MET (25.83 \pm 13.94 hours/day) compared with other groups (analysis of variance, $\mathrm{p}<0.05$ ). Participants in the infant group had the highest level of average BMI (24.02 \pm 3.24$)$ compared with their counterparts (analysis of variance, $\mathrm{p}<0.05$ ). Detailed demographic, socioeconomic and behavioural characteristics of participants are shown in table 1 . The prevalence of RA with age based on all data in the CKB baseline is also shown in online supplemental figure 1 and was consistent with a previous RA study, verifying the validity of our selfreported outcome. ${ }^{26}$

The associations between the different periods of famine exposure and RA in adulthood are presented in table 2. In the two models fitted, the prevalence of RA in adulthood among infant-exposed individuals was significantly higher than the non-exposed individuals (model 1: OR=1.44, 95\% CI 1.25 to 1.67 ; model 2: OR=1.44, 95\% CI 1.24 to $1.67 ; \mathrm{p}<0.001$ ). The prevalence of RA in adulthood among preschoolexposed individuals was significantly higher than the non-exposed individuals (model 1: OR=1.34, 95\% CI 1.19 to 1.50 ; model 2: OR=1.38, 95\% CI 1.22 to 1.57 ; $\mathrm{p}<0.001)$. However, compared with non-exposed individuals, prenatal-exposed individuals had similar odds of getting RA (model 1: OR=1.08, 95\% CI 0.94 to 1.24; model 2: $\mathrm{OR}=1.06,95 \%$ CI 0.92 to 1.23 ; $\mathrm{p}>0.05)$. The results of the age-period-cohort analysis, provided in online supplemental figure 2, also show an increased relative risk of RA in the 1957-1961 cohort, who were exposed to famine in early life.

As shown in table 3, the strength of the association between infant famine exposure and RA in adulthood diverged by residential region, famine severity, sex and BMI, comparing with non-exposed and age-balanced groups. Stratified by region, urban participants who experienced famine in infancy were more likely to report RA in adulthood compared with the non-exposed and age-balanced groups (non-exposed: $\mathrm{OR}=1.57,95 \% \mathrm{CI}$ 1.28 to $1.93, \mathrm{p}<0.001$; age-balanced: $\mathrm{OR}=1.22,95 \% \mathrm{CI}$ 1.02 to $1.46, \mathrm{p}<0.05)$. Stratified by famine severity, participants who experienced severe famine in early life had significantly higher odds of RA in adulthood compared with the non-severe group ( $p$ value for difference $<0.05$ ). Stratified by sex, women who experienced famine in infancy had significantly higher odds of RA in adulthood compared with non-exposed and age-balanced women (non-exposed: $\mathrm{OR}=1.44,95 \%$ CI 1.20 to $1.72, \mathrm{p}<0.001$; age-balanced: $\mathrm{OR}=1.15,95 \%$ CI 1.02 to $1.34, \mathrm{p}<0.05)$. Women who experienced famine in early life had significantly higher odds of RA in adulthood compared with men ( $p$ value for difference $<0.001$ ). Lastly, when stratified by BMI, infant-exposed participants with BMI $\geq 24$ had a significantly higher likelihood of RA in adulthood compared with their non-exposed and age-balanced counterparts (non-exposed: $\mathrm{OR}=1.49,95 \% \mathrm{CI} 1.20$ to 1.83 , $\mathrm{p}<0.001$; age-balanced: $\mathrm{OR}=1.28,95 \% \mathrm{CI} 1.06$ to 1.53 , $\mathrm{p}<0.01$ ). Infant-exposed participants with BMI $\geq 24$ had significantly higher odds of RA in adulthood compared 
Table 1 Characteristics of the study participants by rheumatoid arthritis $(\mathrm{N}=111706)$

\begin{tabular}{|c|c|c|c|c|}
\hline & $\begin{array}{l}\text { Non-exposed } \\
(\mathrm{n}=40038)\end{array}$ & $\begin{array}{l}\text { Prenatal-exposed } \\
(\mathrm{n}=\mathbf{2 2} 413)\end{array}$ & $\begin{array}{l}\text { Infant-exposed } \\
(\mathrm{n}=14899)\end{array}$ & $\begin{array}{l}\text { Preschool-exposed } \\
(n=34356)\end{array}$ \\
\hline Age, years, mean $\pm S D$ & $42.48 \pm 1.23$ & $45.43 \pm 1.29$ & $47.69 \pm 1.14$ & $49.12 \pm 1.24$ \\
\hline RA, n (\%) & $541(1.35)$ & $326(1.45)$ & $289(1.94)$ & $619(1.80)$ \\
\hline Diagnosis year, mean \pm SD & $31.78 \pm 8.92$ & $32.95 \pm 9.92$ & $34.74 \pm 10.69$ & $34.85 \pm 11.01$ \\
\hline \multicolumn{5}{|l|}{ Region, n (\%) } \\
\hline Urban & 22589 (56.42) & $11307(50.45)$ & $7076(47.49)$ & $15367(44.73)$ \\
\hline Non-severe & $13556(60.01)$ & $6833(60.43)$ & $4111(58.10)$ & 9073 (59.04) \\
\hline Severe & 9033 (39.99) & $4474(39.57)$ & $2965(41.90)$ & $6294(40.96)$ \\
\hline Rural & 17449 (43.58) & 11106 (49.55) & $7823(52.51)$ & 18989 (55.27) \\
\hline Non-severe & 3266 (18.72) & 2699 (24.30) & $1559(19.93)$ & $4283(22.56)$ \\
\hline Severe & $14183(81.28)$ & 8407 (75.70) & $6264(80.07)$ & $14706(77.44)$ \\
\hline \multicolumn{5}{|l|}{ Sex, n (\%) } \\
\hline Male & $15182(37.92)$ & 8723 (38.92) & $6021(40.41)$ & 13597 (39.58) \\
\hline Female & $24856(62.08)$ & $13690(61.08)$ & 8878 (59.59) & 20759 (60.42) \\
\hline \multicolumn{5}{|l|}{ Highest education, n (\%) } \\
\hline No formal school & $2058(5.14)$ & $3658(16.32)$ & $2127(14.28)$ & 6507 (18.94) \\
\hline Primary school & 7023 (17.54) & 5809 (25.92) & $3696(24.81)$ & $9413(27.40)$ \\
\hline Middle school & $17625(44.02)$ & $6672(29.77)$ & $4540(30.47)$ & 9945 (28.95) \\
\hline High school & $10450(26.10)$ & $5296(23.63)$ & 3891 (26.12) & $6980(20.32)$ \\
\hline Technical school/college & $1894(4.73)$ & $717(3.20)$ & $475(3.19)$ & $1099(3.20)$ \\
\hline University & $989(2.47)$ & $258(1.15)$ & $170(1.14)$ & $412(1.20)$ \\
\hline \multicolumn{5}{|l|}{ Household income (¥), n (\%) } \\
\hline$<2500$ & $320(0.80)$ & $193(0.86)$ & $170(1.14)$ & $392(1.14)$ \\
\hline 2500-4999 & $1634(4.08)$ & $840(3.75)$ & $691(4.64)$ & $1636(4.76)$ \\
\hline 5000-9999 & $7059(17.63)$ & $3783(16.88)$ & $2599(17.44)$ & 5959 (17.34) \\
\hline $10000-19999$ & $12196(30.46)$ & $7076(31.57)$ & $4664(31.30)$ & $10245(29.82)$ \\
\hline 20000-34 999 & $11351(28.35)$ & $6406(28.58)$ & $4232(28.40)$ & 9395 (27.35) \\
\hline$\geq 35000$ & 7479 (18.68) & $4115(18.36)$ & $2543(17.07)$ & 6729 (19.59) \\
\hline \multicolumn{5}{|l|}{ Alcohol consumption, n (\%) } \\
\hline Non-drinker & $16528(41.28)$ & $8983(40.08)$ & $6118(41.06)$ & $14802(43.08)$ \\
\hline Ex-regular & $276(0.69)$ & $197(0.88)$ & $174(1.17)$ & $414(1.21)$ \\
\hline Occasional drinker & 14410 (35.99) & 7968 (35.55) & $5162(34.65)$ & $11522(33.54)$ \\
\hline Monthly & $1814(4.53)$ & $1060(4.73)$ & $558(3.75)$ & $1252(3.64)$ \\
\hline Reduced intake & $657(1.64)$ & $408(1.82)$ & $302(2.03)$ & $693(2.02)$ \\
\hline Weekly & $6354(15.87)$ & 3797 (16.94) & 2585 (17.35) & $5673(16.51)$ \\
\hline \multicolumn{5}{|l|}{ Tobacco use, n (\%) } \\
\hline Non-smoker & $26141(65.29)$ & $14248(63.57)$ & $9183(61.64)$ & 21432 (62.38) \\
\hline Occasional smoker & $2338(5.84)$ & $1213(5.41)$ & $789(5.30)$ & $1724(5.02)$ \\
\hline Ex-smoker & $1205(3.01)$ & $843(3.76)$ & $646(4.34)$ & $1502(4.37)$ \\
\hline Frequent smoker & $10358(25.87)$ & $6110(27.26)$ & 4281 (28.73) & $9698(28.23)$ \\
\hline MET, hours/day & $25.83 \pm 13.94$ & $24.93 \pm 14.03$ & $23.56 \pm 14.15$ & $23.86 \pm 14.00$ \\
\hline $\mathrm{BMI}$, mean $\pm \mathrm{SD}$ & $23.81 \pm 3.23$ & $23.96 \pm 3.20$ & $24.02 \pm 3.24$ & $23.95 \pm 3.25$ \\
\hline $\mathrm{BMI}<24, \mathrm{n}(\%)$ & 22063 (55.11) & 11826 (52.76) & 7744 (51.98) & 18106 (52.70) \\
\hline $\mathrm{BMI} \geq 24, \mathrm{n}(\%)$ & 17975 (44.89) & $10587(47.24)$ & 7155 (48.02) & $16250(47.30)$ \\
\hline
\end{tabular}

BMI, body mass index; MET, metabolic equivalent of task hours; RA, rheumatoid arthritis. 
Table 2 OR for getting rheumatoid arthritis in different famine exposure groups

\begin{tabular}{lllll} 
& Non-exposed group & Prenatal-exposed group & Infant-exposed group & Preschool-exposed group \\
\hline Model 1 & 1 & $1.08(0.94$ to 1.24$)$ & $1.44(1.25 \text { to } 1.67)^{\star \star \star}$ & $1.34(1.19 \text { to } 1.50)^{\star \star \star}$ \\
Model 2 & 1 & $1.06(0.92$ to 1.23$)$ & $1.44(1.24 \text { to } 1.67)^{\star \star \star}$ & $1.38(1.22 \text { to } 1.57)^{\star \star \star}$
\end{tabular}

Model 1 did not adjust for any covariate. Model 2 adjusted for sex, region, monthly income, highest education level, alcohol consumption, tobacco use, body mass index and metabolic equivalent of task hours.

${ }^{* * \star *} \mathrm{P}<0.001$.

with infant-exposed participants with $\mathrm{BMI}<24$ ( $\mathrm{p}$ value for difference $<0.001)$.

\section{DISCUSSION}

The results verified our speculation that early-life famine exposure was associated with later-life RA. We further found this association existed for those exposed to famine during the period after birth, especially stronger in infancy, rather than the prenatal period. Moreover, when stratified by sex, residing region, famine severity and BMI, the association was found among urban residents and women and was stronger among participants with $\mathrm{BMI} \geq 24$ and in severe famine region.
Our result was consistent with the previous two studies on famine and arthritis. Wang et $a l^{18}$ and Xu et al ${ }^{17}$ reported an OR of 1.50 (1.21-1.85) and 1.656 (1.095-2.505), respectively, among individuals exposed to famine during infancy. However, our findings further indicated infant exposure to famine could be a vital cause specifically of RA, as both studies used arthritis as their outcomes. The findings were further verified by the stronger association between severe famine exposure and RA compared with non-severe famine exposure. RA is associated with most components of the MetS, ${ }^{27}$ for instance, body weight changes. The finding that the odds ratio was higher in the group with $\mathrm{BMI} \geq 24$ suggested a potentially link between

Table 3 OR for getting rheumatoid arthritis among the infant-exposed group comparing with two reference groups, stratified by region, sex and BMI

\begin{tabular}{|c|c|c|}
\hline Stratified factors & $\begin{array}{l}\text { Infant-exposed group (reference: non-exposed } \\
\text { group) }\end{array}$ & $\begin{array}{l}\text { Infant-exposed group (reference: age-balanced } \\
\text { groupt) }\end{array}$ \\
\hline & $1.44(1.28 \text { to } 1.63)^{\star \star \star}$ & $1.17(1.03 \text { to } 1.336)^{*}$ \\
\hline \multicolumn{3}{|l|}{ Region } \\
\hline Rural & $1.31(1.05 \text { to } 1.63)^{*}$ & 1.12 (0.92 to 1.37$)$ \\
\hline Non-severe & 1.20 (0.90 to 1.60$)$ & 1.10 (0.84 to 1.42$)$ \\
\hline Urban & $1.57(1.28 \text { to } 1.93)^{\star \star \star}$ & $1.22(1.02 \text { to } 1.46)^{*}$ \\
\hline Non-severe & $1.46(1.09 \text { to } 1.94)^{\star \star}$ & 1.19 (0.92 to 1.52$)$ \\
\hline Severe & $1.80(1.24 \text { to } 2.60)^{\star \star}$ & 1.27 (0.92 to 1.74$)$ \\
\hline$P$ value for difference & $<0.001$ & $<0.001$ \\
\hline$P$ value for difference & $<0.001$ & $<0.001$ \\
\hline \multicolumn{3}{|l|}{ BMI } \\
\hline $\mathrm{BMI}<24$ & $1.40(1.13 \text { to } 1.73)^{\star \star}$ & 1.07 (0.88 to 1.30$)$ \\
\hline $\mathrm{BMI} \geq 24$ & $1.49(1.20 \text { to } 1.83)^{\star \star \star}$ & $1.28(1.06 \text { to } 1.53)^{\star \star}$ \\
\hline$P$ value for difference & $<0.001$ & $<0.001$ \\
\hline
\end{tabular}

All analyses were adjusted for monthly income, highest education, alcohol consumption, tobacco use, BMI and metabolic equivalent of task hours.

${ }^{*} \mathrm{P}<0.05,{ }^{* \star} \mathrm{P}<0.01,{ }^{* \star *} \mathrm{P}<0.001$.

†Combined prenatal-exposed and preschool-exposed groups.

BMI, body mass index. 
famine and MetS. A study showed that the odds of MetS are significantly higher in infant-exposed individuals rather than fetal-exposed or preschool-exposed groups compared with the non-exposed group,${ }^{28}$ also implying the common underlying pathogenesis of RA and MetS.

The immunopathogenesis of RA could explain the relationship found between famine and RA. RA-specific immune reactions might originate in extra-articular locations, particularly in the mucosal sites such as the intestinal mucosa. Severe acute malnutrition leads to alterations in the gut microbiota. ${ }^{29}$ Alterations in compositional diversity and abundance levels of the microbiota, that is, dysbiosis, lead to mucosal disequilibrium in several types of autoimmune and inflammatory diseases, like RA. Through imbalance in $\mathrm{T}$ cell subpopulations, this local autoimmunity may progress to systemic disease in some cases. ${ }^{30}$ Dysbiosis in mucosal sites may also break in selftolerance to citrullinated autoantigens, ${ }^{31}$ and led to the production of anticitrullinated protein antibody (APCA). APCA, a type of RA-associated antibodies that exist in the blood long before joint inflammation, ${ }^{32}$ might be important in the transition from preclinical phase to a clinical expression of RA.

In addition, intestinal microbiota were thought to be the most important source of maturational stimuli for the development of immune system. Gut microbial ecology and function were almost sterile in the fetus, dynamic in infancy, but stabilised in childhood. ${ }^{10}$ Especially in the first year, the gut microbiota dramatically change through interactions with the developing immune system, impacting greatly on the development of the host immune system, with the potential to be the main determinant of lifelong health. ${ }^{10}$ This may explain why the association between famine exposure and RA was higher in the infant-exposed group and insignificant in the prenatal-exposed group.

The relationship between famine exposure and RA, which was stronger in urban regions than in rural regions, could be explained by the following reasons. First, there was limited availability in healthcare services in rural regions and therefore RA rates might be under-reported due to detection bias. In addition, configurations of the gut microbiome varied across urban and rural populations, as environmental exposures during urbanisation, such as westernisation of diet, increasing antibiotic use and pollution, might affect the gut microbiota. ${ }^{33}$ Urban residents, thus, showed a decrease in the diversity and richness of the gut microbiota, ${ }^{34}$ which might have a role in the pathogenesis of RA. Furthermore, early-life malnutrition and later-life nutritionally rich environment were related to a higher risk of MetS, which has an established correlation with RA. ${ }^{35}$ Specifically, people in urban regions consume more meat, sugar and edible oil and fewer crops and vegetables than their rural counterparts, ${ }^{37}$ resulting in a higher risk for overload nutrition. Metabolic-triggered inflammation caused by nutrient overload and metabolic surplus consists of components (such as proinflammatory cytokines, adipokines and vitamin $\mathrm{D}$ deficiency) that may contribute to the onset of RA. ${ }^{38}$ Moreover, in the past 30 years, there have been waves of huge one-way migration from rural to urban regions. Many people exposed to famine in early life in rural regions migrated to cities, where they experienced overload nutrition, which might also explain the higher odds of RA in urban regions.

Women experiencing famine in early life had higher odds of RA. Among women, a relationship was also found between odds of RA and other famine-related diseases such as obesity, hypertension and cardiovascular disease. ${ }^{39}{ }^{40}$ Women exposed to famine in early life were more likely to have MetS, while similar prevalence was found between men with and without early-life famine experiences. ${ }^{13}{ }^{41}$ Hormones may play an important role in the mechanism because starvation leads to an increase in the secretion of androgen. ${ }^{42}$ Brand $e t a t^{33}$ showed that men at the highest tertile of total testosterone had lower odds of incident MetS, while women at the highest tertile of total testosterone had increased odds of incident MetS. Janssen $e t a t^{44}$ and Soriguer $e t a t^{45}$ also noted more androgenic environment was associated with incident MetS in women. Furthermore, sex differences in the gut microbiota composition exist. ${ }^{46}$ An interaction exists between the gut microbiota and sex hormones. Whereas the level of $17 \beta$-oestradiol was not different between germ-free (GF) and specific pathogen-free (SPF) mice, the level of testosterone was higher in the GF female mice than in the SPF female mice and lower in the GF male mice than in the SPF male mice. ${ }^{47}$ Moreover, sex discrimination, where boys are considered to be of greater importance in traditional Chinese culture, may also contribute to the more severe food shortage among girls. ${ }^{41}$ Besides, the male mortality was higher than female mortaliy during the Great Famine, leading to a potential survival bias of male participants. Thus, male participants may have better outcomes during adulthood. ${ }^{41} 48$

Our results are in good agreement with previous studies on early predictors of RA. Previous studies showed that breast feeding, a symbol of adequate nutrition in early life, was associated with reduced risk of $\mathrm{RA}^{49}$; obesity, MetS and type 2 diabetes, proven to be related to early malnutrition, ${ }^{512} 1350$ were risk factors for the development of RA in adulthood. ${ }^{51}{ }^{52}$ Our research provided direct evidence that RA was associated with early malnutrition. Besides, it also indicated that changes in these indicators and diseases may follow the same mechanism chain, which was likely to be an immune response chain, and required further studies.

\section{Strengths and limitations}

To our knowledge, this study was the first to explore the association between famine exposure in early life and RA in adulthood. Previous studies examined the association between early-life famine exposure and adult arthritis in general $^{1718}$ and neglected differences in the pathogenesis behind the subtypes of arthritis. Second, the study population had high representativeness of the original 
large population, with a wide geographical distribution covering 10 provinces. Third, the interaction between sex and region had been fully considered. Admittedly, some potential limitations of the present study exist. First, RA data were self-reported. Although there were professional investigators who provided information on RA to guide participants, data on RA may be confused with other arthritis. However, the prevalence rate and the average ages of onset of RA in this study were consistent with the characteristics of RA, which indicates the validity of the survey to some degree. Second, the study lacks measurements of famine exposure at the individual level. Individual famine exposure in early life cannot be collected using a self-reported survey questionnaire. Nonetheless, since the Great Chinese Famine was widespread in all provinces in 1959-1961, we assumed that everyone born during this period was affected. Third, current addresses rather than addresses during the famine period were collected. Since the migration rate did not exceed $2 \%$ before 1990 and did not exceed 10\% after 1990 nationwide, and the migrants were mainly young people with the mean age in the mid-20s, which did not coincide with the age groups of our participants, misclassification bias could be avoided to a large degree. ${ }^{53}$

\section{CONCLUSION}

In conclusion, infant famine exposure was associated with higher odds of RA in the adult life, and this effect appeared significant among urban residents and women and stronger in participants with BMI $\geq 24$. The current study showed that malnutrition during infancy may be a risk factor for the aetiology of RA in adult life, and thus infant nutrition should be given more attention to prevent RA in later life. Further studies with precise biological indicators and early predictors of RA should be conducted to confirm the relationship. Future population studies and experimental studies are needed to help establish the underlying biological and physiological mechanisms for the associations between early-life malnutrition and immune diseases such as RA in the present study.

Acknowledgements We are grateful to the Clinical Trial Service Unit and Epidemiological Studies Unit (CTSU), Nuffield Department of Population Health, University of Oxford, Oxford, UK, for providing the data. XM acknowledges support from the Shuimu Tsinghua Scholar Program, Tsinghua University.

Contributors $\mathrm{KT}$ and XM conceived the study, and XM and $\mathrm{CL}$ contributed to the study design. CL performed the data analysis and wrote the manuscript. HZ, FY and XP contributed to revisions. All authors critically reviewed the manuscript and contributed important intellectual content. All authors have read and approved the manuscript as submitted.

Funding The authors have not declared a specific grant for this research from any funding agency in the public, commercial or not-for-profit sectors.

Competing interests None declared.

Patient consent for publication Not required.

Ethics approval The study was approved by the Ethical Review Committee of the Chinese Center for Disease Control and Prevention (Beijing, China) (ethics ID number of approval: 005/2004) and the Oxford Tropical Research Ethics Committee, University of Oxford (UK) (ethics ID number of approval: OXTREC 025-04).

Provenance and peer review Not commissioned; externally peer reviewed.

Data availability statement Data are available in a public, open access repository. The data set supporting the conclusions of this article is available from the study website (http://www.ckbiobank.org), along with the access policy and procedures.

Supplemental material This content has been supplied by the author(s). It has not been vetted by BMJ Publishing Group Limited (BMJ) and may not have been peer-reviewed. Any opinions or recommendations discussed are solely those of the author(s) and are not endorsed by BMJ. BMJ disclaims all liability and responsibility arising from any reliance placed on the content. Where the content includes any translated material, BMJ does not warrant the accuracy and reliability of the translations (including but not limited to local regulations, clinical guidelines, terminology, drug names and drug dosages), and is not responsible for any error and/or omissions arising from translation and adaptation or otherwise.

Open access This is an open access article distributed in accordance with the Creative Commons Attribution Non Commercial (CC BY-NC 4.0) license, which permits others to distribute, remix, adapt, build upon this work non-commercially, and license their derivative works on different terms, provided the original work is properly cited, appropriate credit is given, any changes made indicated, and the use is non-commercial. See: http://creativecommons.org/licenses/by-nc/4.0/.

ORCID iD

Kun Tang http://orcid.org/0000-0002-5444-186X

\section{REFERENCES}

1 Cross M, Smith E, Hoy D, et al. The global burden of rheumatoid arthritis: estimates from the global burden of disease 2010 study. Ann Rheum Dis 2014;73:1316-22.

2 Gunnarsson C, Chen J, Rizzo JA, et al. The employee absenteeism costs of rheumatoid arthritis: evidence from US national survey data. J Occup Environ Med 2015;57:635-42.

3 England BR, Thiele GM, Anderson DR, et al. Increased cardiovascular risk in rheumatoid arthritis: mechanisms and implications. BMJ 2018;361:k1036.

4 Lee DM, Weinblatt ME. Rheumatoid arthritis. Lancet 2001;358:903-11.

$5 \mathrm{Li} \mathrm{Y,} \mathrm{Jaddoe} \mathrm{VW,} \mathrm{Qi} \mathrm{L,} \mathrm{et} \mathrm{al.} \mathrm{Exposure} \mathrm{to} \mathrm{the} \mathrm{Chinese} \mathrm{famine} \mathrm{in} \mathrm{early}$ life and the risk of metabolic syndrome in adulthood. Diabetes Care 2011;34:1014-8.

6 Eriksson J, Forsén T, Tuomilehto J, et al. Fetal and childhood growth and hypertension in adult life. Hypertension 2000;36:790-4.

7 Jones C. Foetal programming and coronary heart disease in later life. Br J Nurs 2002;11:822-6.

8 Crowson CS, Liao KP, Davis JM, et al. Rheumatoid arthritis and cardiovascular disease. Am Heart J 2013;166:622-8.

9 M-C L, Yan S-T, Yin W-Y. Risk of rheumatoid arthritis in patients with type 2 diabetes: a nationwide population-based case-control study. PLoS One 2014;9:e101528-e28.

10 Tanaka M, Nakayama J. Development of the gut microbiota in infancy and its impact on health in later life. Allergol Int 2017;66:515-22.

11 Smil V. China's great famine: 40 years later. BMJ 1999;319:1619-21.

$12 \mathrm{Li} \mathrm{Y,} \mathrm{He} \mathrm{Y,} \mathrm{Qi} \mathrm{L,} \mathrm{et} \mathrm{al.} \mathrm{Exposure} \mathrm{to} \mathrm{the} \mathrm{Chinese} \mathrm{famine} \mathrm{in} \mathrm{early} \mathrm{life} \mathrm{and}$ the risk of hyperglycemia and type 2 diabetes in adulthood. Diabetes 2010;59:2400-6.

13 Zheng X, Wang Y, Ren W, et al. Risk of metabolic syndrome in adults exposed to the great Chinese famine during the fetal life and early childhood. Eur J Clin Nutr 2012;66:231-6.

14 Huang C, Li Z, Wang M, et al. Early life exposure to the 19591961 Chinese famine has long-term health consequences. $J$ Nutr 2010;140:1874-8.

15 Chen Y, Zhou L-A. The long-term health and economic consequences of the 1959-1961 famine in China. $J$ Health Econ 2007;26:659-81.

16 Wang $Y$, Wang $X$, Kong $Y$, et al. The great Chinese famine leads to shorter and overweight females in Chongqing Chinese population after 50 years. Obesity 2010;18:588-92.

$17 \mathrm{Xu} \mathrm{X,} \mathrm{Liu} \mathrm{L,} \mathrm{Xie} \mathrm{W,} \mathrm{et} \mathrm{al.} \mathrm{Increase} \mathrm{in} \mathrm{the} \mathrm{prevalence} \mathrm{of} \mathrm{arthritis} \mathrm{in}$ adulthood among adults exposed to Chinese famine of 1959 to 1961 during childhood: a cross-sectional survey. Medicine 2017;96:e6496.

18 Wang Z, Zou Z, Dong B, et al. Association between the great China famine exposure in early life and risk of arthritis in adulthood. $J$ Epidemiol Community Health 2018;72:790-5. 
19 Chen Z, Chen J, Collins R, et al. China Kadoorie Biobank of 0.5 million people: survey methods, baseline characteristics and longterm follow-up. Int J Epidemiol 2011;40:1652-66.

20 Tang K, Zhao Y, Li C. The association between self-rated health and different anthropometric and body composition measures in the Chinese population. BMC Public Health 2017;17:317-17.

21 Yu C, Wang J, Li Y, et al. Exposure to the Chinese famine in early life and hypertension prevalence risk in adults. $J$ Hypertens 2017;35:63-8.

22 Yang Z, Zhao W, Zhang X, et al. Impact of famine during pregnancy and infancy on health in adulthood. Obes Rev 2008;9 Suppl 1:95-9.

23 Lumey LH. Reproductive outcomes in women prenatally exposed to undernutrition: a review of findings from the Dutch famine birth cohort. Proc Nutr Soc 1998;57:129-35

24 Ainsworth BE, Haskell WL, Herrmann SD, et al. 2011 compendium of physical activities: a second update of codes and Met values. Med Sci Sports Exerc 2011;43:1575-81.

25 Peng X. Demographic Consequences of the Great Leap Forward in China's Provinces. Popul Dev Rev 1987;13:639-70.

26 Abhishek A, Doherty M, Kuo C-F, et al. Rheumatoid arthritis is getting less frequent-results of a nationwide population-based cohort study. Rheumatology 2017;56:kew468-44.

27 Ferraz-Amaro I, González-Juanatey C, López-Mejias R, et al. Metabolic syndrome in rheumatoid arthritis. Mediators Inflamm 2013;2013:1-11.

28 Wang Z, Zou Z, Wang S, et al. Chinese famine exposure in infancy and metabolic syndrome in adulthood: results from the China health and retirement longitudinal study. Eur J Clin Nutr 2019;73:724-32.

29 Million M, Diallo A, Raoult D. Gut microbiota and malnutrition. Microb Pathog 2017;106:127-38.

30 Lee N, Kim W-U. Microbiota in T-cell homeostasis and inflammatory diseases. Exp Mol Med 2017;49:e340.

31 Holers VM. Autoimmunity to citrullinated proteins and the initiation of rheumatoid arthritis. Curr Opin Immunol 2013;25:728-35.

32 Dong X, Zheng Z, Zhai Y, et al. Acpa mediates the interplay between innate and adaptive immunity in rheumatoid arthritis. Autoimmun Rev 2018;17:845-53.

33 Zuo T, Kamm MA, Colombel J-F, et al. Urbanization and the gut microbiota in health and inflammatory bowel disease. Nat Rev Gastroenterol Hepatol 2018;15:440-52

34 Martínez I, Stegen JC, Maldonado-Gómez MX, et al. The gut microbiota of rural Papua New Guineans: composition, diversity patterns, and ecological processes. Cell Rep 2015;11:527-38.

35 Wu L, Feng X, He A, et al. Prenatal exposure to the great Chinese famine and mid-age hypertension. PLoS One 2017;12:e0176413.

36 Karvounaris SA, Sidiropoulos PI, Papadakis JA, et al. Metabolic syndrome is common among middle-to-older aged Mediterranean patients with rheumatoid arthritis and correlates with disease activity: a retrospective, cross-sectional, controlled, study. Ann Rheum Dis 2007:66:28-33.
37 Yang Y, Hu X-M, Chen T-J, et al. Rural-Urban differences of dietary patterns, overweight, and bone mineral status in Chinese students. Nutrients 2016;8:537.

38 Wang $\mathrm{X}$, Hunter $\mathrm{D}, \mathrm{Xu}$ J, et al. Metabolic triggered inflammation in osteoarthritis. Osteoarthritis Cartilage 2015;23:22-30.

39 Ravelli AC, van Der Meulen JH, Osmond C, et al. Obesity at the age of $50 \mathrm{Y}$ in men and women exposed to famine prenatally. Am J Clin Nutr 1999;70:811-6.

40 Shi Z, Nicholls SJ, Taylor AW, et al. Early life exposure to Chinese famine modifies the association between hypertension and cardiovascular disease. J Hypertens 2018;36:54-60.

41 Wang N, Wang X, Li Q, et al. The famine exposure in early life and metabolic syndrome in adulthood. Clin Nutr 2017;36:253-9.

42 Kempná P, Hirsch A, Hofer G, et al. Impact of differential P450c17 phosphorylation by cAMP stimulation and by starvation conditions on enzyme activities and androgen production in NCl-H295R cells. Endocrinology 2010;151:3686-96.

43 Brand JS, van der Tweel I, Grobbee DE, et al. Testosterone, sex hormone-binding globulin and the metabolic syndrome: a systematic review and meta-analysis of observational studies. Int J Epidemiol 2011;40:189-207.

44 Janssen I, Powell LH, Crawford S, et al. Menopause and the metabolic syndrome: the study of women's health across the nation. Arch Intern Med 2008;168:1568-75.

45 Soriguer F, Rubio-Martín E, Fernández D, et al. Testosterone, SHBG and risk of type 2 diabetes in the second evaluation of the Pizarra cohort study. Eur J Clin Invest 2012;42:79-85.

46 Arumugam M, Raes J, Pelletier E, et al. Enterotypes of the human gut microbiome. Nature 2011;473:174-80.

47 Markle JGM, Frank DN, Mortin-Toth S, et al. Sex differences in the gut microbiome drive hormone-dependent regulation of autoimmunity. Science 2013;339:1084-8.

48 Mu R, Zhang X. Gender difference in the long-term impact of famine. International Food Policy Research Institute (IFPRI), IFPRI discussion papers 2008.

49 Jacobsson LTH, Jacobsson ME, Askling J, et al. Perinatal characteristics and risk of rheumatoid arthritis. BMJ 2003;326:1068-9.

50 Ravelli AC, van der Meulen $\mathrm{JH}$, Osmond $\mathrm{C}$, et al. Obesity at the age of $50 \mathrm{Y}$ in men and women exposed to famine prenatally. Am J Clin Nutr 1999;70:811-6.

51 Ohno T, Aune D, Heath AK. Adiposity and the risk of rheumatoid arthritis: a systematic review and meta-analysis of cohort studies. Sci Rep 2020;10:1-12.

52 Haimuzi X, Choi S-E, Kang J-K. Basal metabolic rate and Charlson comorbidity index are independent predictors of metabolic syndrome in patients with rheumatoid arthritis. Joint Bone Spine 2020.

53 Li C, Lumey LH. Exposure to the Chinese famine of 1959-61 in early life and long-term health conditions: a systematic review and metaanalysis. Int J Epidemiol 2017;46:1157-70. 